(C) 1984. The Genetical Society of Great Britain

\title{
POLYMORPHISM FOR OUTCROSSING FREQUENCY AT THE RAY FLORET LOCUS IN SENECIO VULGARIS L. II. CONFIRMATION.
}

\author{
DAVID F. MARSHALL* AND RIĆHARD J. ABBOTT \\ Department of Botany, University of St, Andrews, St. Andrews, Fife, KY16 9AL, U.K.
}

Received 29.ix.83

\section{SUMMARY}

\begin{abstract}
A survey of outcrossing rates at the ray floret locus in an Edinburgh population of Senecio vulgaris in 1979 and 1980 showed that in both years radiate plants outcrossed at much greater frequencies than non-radiate plants. This confirmed a difference previously found between the two morphs in two Edinburgh populations investigated in 1978 (Marshall and Abbott, 1982). The size of the difference at peak flowering periods varied greatly between years, reaching 35 per cent in June 1979 then falling to 7 per cent in May 1980. An extension of the survey to include large populations polymorphic at the ray floret locus, from Leeds, Cardiff and Rhosllanerchrugog (Clwyd) revealed a similar pattern of genotypic differences in outcrossing. It is concluded that the difference is a general feature of the ray floret polymorphism in $S$. vulgaris.
\end{abstract}

\section{INTRODUCTION}

Recent detailed analysis of outcrossing rates in self-compatible plants reveals a picture of widespread variability. Variations in outcrossing frequency have been reported both between and within populations of single species (Hamrick, 1982; Schoen, 1982) and in many instances are heritable. Often the variability is of a continuous nature and can be determined, for example, by minor differences between plants in flower size, anther-stigma distance (Breese, 1959; Ennos, 1981), degree of protogyny or protandry (Schoen, 1982), or the ratio of cleistogamous to chasmogamous flowers (Clay, 1982). The factors responsible for the origin and maintenance of intrapopulation variation in outcrossing rates are yet to be elucidated though it is recognised that the effects of such variation on genotypic structure and evolutionary potential may be considerable. A determination of the responsible factors is more likely to emerge from an analysis of situations where the variability in outcrossing frequency is discontinuous rather than continuous, and there is a single gene polymorphism for outcrossing rate.

Recently, Marshall and Abbott (1982) have reported a single gene polymorphism for outcrossing frequency at the ray floret locus in the groundsel, Senecio vulgaris L. (Compositae). In two wild polymorphic populations of $S$. vulgaris located in Edinburgh, plants lacking ray florets and therefore homozygous for the non-radiate allele (Trow, 1912) were found to outcross at very low frequencies ( $<1$ per cent) whereas radiate plants that are homozygous for the alternative, radiate allele always showed

* Present address: Department of Genetics, University of Birmingham, P.O. Box 363, Birmingham, B15 2TT. 
much greater "female" outcrossing levels reaching 13-20 per cent during peak flowering periods.

Marshall and Abbott (1982) suggested that the possession of pistillate ray florets by capitula of radiate plants leads to the occurrence of functional protogyny which in turn is likely to greatly boost the outcrossing frequency of radiate plants relative to that of non-radiate plants. Alternatively or in addition, the difference in outcrossing between morphs could be a product of local or widespread linkage disequilibrium between alleles at the ray floret locus and alleles at one or more loci affecting outcrossing. Such a disequilibrium might result from random effects or selection.

Should the association between outcrossing rates and genotype in the two Edinburgh populations studied in 1978 be entirely the result of random linkage disequilibrium, then it is to be expected that recombination might eventually break the relationship and that in future generations, there would be a decay in the disequilibrium. Moreover, an investigation of polymorphic populations at localities elsewhere in Britain should reveal no consistent relationship between outcrossing and genotype at the ray floret locus.

With the above in mind, it was decided to broaden the analysis of outcrossing variation at the ray floret locus in $S$. vulgaris by (i) continuing the survey of outcrossing frequency in one of the two Edinburgh populations initially studied in 1978; and (ii) examining outcrossing rates in other British polymorphic populations of $S$. vulgaris. The results of these further investigations are reported in the present paper.

\section{Materials AND Methods}

A population from Newhaven Road, Edinburgh, previously investigated by Marshall and Abbott (1982) in 1978, was subjected to further survey in June 1979 and in April, May and August, 1980. Periodic dumping of waste material at the site throughout the survey made available new areas for colonisation by $S$. vulgaris as the species became excluded from the original sites by other more competitive species.

In June and July 1979 a search was conducted for populations of $S$. vulgaris, polymorphic at the ray floret locus, in towns and cities located in North and Central England and North and South Wales. Large populations comparable to the Edinburgh population, were found at Leeds, Cardiff, and at Rhosllanerchrugog in Clwyd, N. Wales. Each population occurred on open wasteground along with the related species Senecio squalidus L. In the Leeds population the distribution of the radiate morph was noticeably non-random while a distinguishing feature of the population at Rhosllanerchrugog was the occurrence of both yellow and cream variants of the radiate morph (see Trow, 1912).

All populations were surveyed in a similar manner. A total count was made of the numbers of flowering plants which could be assigned to each of the three genotypes at the ray floret locus and in addition seed samples were taken from 50 yellow radiate and 50 non-radiate plants for progeny testing. From the survey and progeny tests, estimates were obtained of genotype and gene frequencies, Wrights Fixation Index, $F$, and outcrossing frequencies (at the ray floret locus) for both radiate and non-radiate plants by the methods which have been described previously (Marshall and Abbott, 1982). 


\section{Results}

\section{(i) The Edinburgh population}

In June 1979 and in April, May and August 1980 the number of flowering plants on the Edinburgh site at Newhaven Road (table 1) exceeded 500 individuals showing that a large population of groundsel was maintained throughout the survey period. Levels of heterozygosity at the ray floret locus were low, as was expected from the mating system and the 1978 survey, and were reflected in the fixation indices which exceeded 0.9 in all four samples. The frequency of the radiate allele was higher in June 1979, 0.696 , than in the corresponding month of $1978,0.415$ (see Marshall and Abbott, 1982), but declined in the final sample taken in August 1980 to 0.369 , a value very similar to the frequency of 0.356 previously recorded at the site in August 1978 (Marshall and Abbott, 1982). The large changes of gene frequency between years were not unexpected at this site. Irregular dumping of waste material throughout the survey period, caused radical alterations in site topography and the occasional loss of large parts of the extant population. This, together with the possible introduction of "foreign" seed along with the waste, is likely to have caused large and random changes in the genotypic structure of the local population from year to year.

TABLE 1

Number of flowering plants, frequencies of the radiate $\left(T_{r} T_{r}\right)$, intermediate $\left(T_{r} T_{n}\right)$ and nonradiate $\left(\mathrm{T}_{\mathrm{n}} \mathrm{T}_{\mathrm{n}}\right)$ genotypes, Wright's Fixation Index $(\mathrm{F})$ and the frequency of the radiate allele in the Edinburgh population at Newhaven Road, 1979 and 1980. Standard errors are in parentheses

\begin{tabular}{ccccc}
\hline Date & June & April & May & August \\
& 1979 & 1980 & 1980 & 1980 \\
\hline Flowering plants & 863 & 890 & 1700 & 549 \\
$\mathrm{~T}_{\mathrm{r}} \mathrm{T}_{\mathrm{r}}$ & 0.688 & 0.494 & 0.427 & 0.351 \\
$\mathrm{~T}_{\mathrm{r}} \mathrm{T}_{\mathrm{n}}$ & 0.015 & 0.010 & 0.011 & 0.035 \\
$\mathrm{~T}_{\mathrm{n}} \mathrm{T}_{\mathrm{n}}$ & 0.297 & 0.496 & 0.562 & 0.614 \\
$\mathrm{~F}$ & 0.964 & 0.980 & 0.977 & 0.926 \\
& $( \pm 0.010)$ & $( \pm 0.007)$ & $( \pm 0.006)$ & $( \pm 0.017)$ \\
$\mathrm{T}_{\mathrm{r}}$ & 0.696 & 0.499 & 0.432 & 0.369 \\
& $( \pm 0.016)$ & $( \pm 0.017)$ & $( \pm 0.012)$ & $( \pm 0.020)$ \\
\hline
\end{tabular}

The difference in outcrossing frequency between the radiate and nonradiate morphs first recorded in 1978 (Marshall and Abbot, 1982) was maintained in the two subsequent years, reaching a peak in 1979, table 2 . Through 1980 the difference tended to be smaller in magnitude than in previous years and was not significant in the August sample.

\section{(ii) The Leeds, Cardiff and Rhosllanerchrugog populations}

These three populations differed greatly in both size of the flowering population, 682 at Rhosllanerchrugog to 7597 at Cardiff, and in the frequency of the radiate allele, 0.062 at Leeds to 0.635 at Cardiff, table 3 . Moreover, the population at Rhosllanerchrugog in contrast with the other two, was characterised by a comparatively high frequency of heterozygotes reflected in a fixation index value of $\mathbf{0 \cdot 8 2 9}$. 
TABLE 2

Outcrossing frequencies $(t)$ of radiate $\left(T_{r} T_{r}\right)$ and non-radiate $\left(T_{n} T_{n}\right)$ plants in the Edinburgh population at Newhaven Road, 1979 and 1980, with heterogeneity $\chi^{2}$ comparisons. Standard errors of estimates are in parentheses

\begin{tabular}{ccccc}
\hline Date & June & April & May & August \\
& 1979 & 1980 & 1980 & 1980 \\
\hline \multirow{2}{*}{$\left(\mathrm{T}_{\mathrm{r}} \mathrm{T}_{\mathrm{r}}\right)$} & $0 \cdot 357$ & $0 \cdot 072$ & $0 \cdot 072$ & $0 \cdot 045$ \\
& $( \pm 0 \cdot 044)$ & $( \pm 0 \cdot 013)$ & $( \pm 0 \cdot 009)$ & $( \pm 0 \cdot 011)$ \\
$\mathrm{t}\left(\mathrm{T}_{\mathrm{n}} \mathrm{T}_{\mathrm{n}}\right)$ & $0 \cdot 003$ & $0 \cdot 002$ & $0 \cdot 009$ & $0 \cdot 022$ \\
$( \pm 0 \cdot 002)$ & $( \pm 0 \cdot 002)$ & $( \pm 0 \cdot 003)$ & $( \pm 0 \cdot 010)$ \\
$\chi_{(1)}^{2}$ & $65 \cdot 8^{* * *}$ & $29 \cdot 5^{* * *}$ & $45 \cdot 4^{* * *}$ & $2 \cdot 4 \mathrm{~N} . \mathrm{S}$. \\
\hline
\end{tabular}

TABLE 3

Number of flowering plants, frequencies of the radiate $\left(\mathrm{T}_{\mathrm{r}} \mathrm{T}_{\mathrm{r}}\right)$, intermediate $\left(\mathrm{T}_{\mathrm{r}} \mathrm{T}_{\mathrm{n}}\right)$ and non-radiate $\left(\mathrm{T}_{\mathrm{n}} \mathrm{T}_{\mathrm{n}}\right)$ genotypes, Wright's Fixation Index $(\mathrm{F})$ and the frequency of the radiate allele in populations at Leeds, Cardiff and Rhosllanerchrugog, 1979. Standard errors are in parenthesis

\begin{tabular}{cccc}
\hline Population & $\begin{array}{c}\text { Leeds } \\
\text { June 1979 }\end{array}$ & $\begin{array}{c}\text { Cardiff } \\
\text { June } 1979\end{array}$ & $\begin{array}{c}\text { Rhosllanerchugog } \\
\text { July 1979 }\end{array}$ \\
\hline Flowering plants & 1047 & 7597 & 682 \\
$\mathrm{~T}_{\mathrm{r}} \mathrm{T}_{\mathrm{r}}$ & $0 \cdot 059$ & $0 \cdot 630$ & $0 \cdot 482$ \\
$\mathrm{~T}_{\mathrm{r}} \mathrm{T}_{\mathrm{n}}$ & $0 \cdot 006$ & $0 \cdot 007$ & $0 \cdot 085$ \\
$\mathrm{~T}_{\mathrm{n}} \mathrm{T}_{\mathrm{n}}$ & $0 \cdot 935$ & $0 \cdot 363$ & $0 \cdot 433$ \\
$\mathrm{~F}$ & $0 \cdot 951$ & $0 \cdot 985$ & $0 \cdot 829$ \\
& $( \pm 0 \cdot 020)$ & $( \pm 0 \cdot 002)$ & $( \pm 0 \cdot 021)$ \\
$\mathrm{T}_{\mathrm{r}}$ & $0 \cdot 062$ & $0 \cdot 633$ & $0 \cdot 525$ \\
& $( \pm 0 \cdot 007)$ & $( \pm 0 \cdot 006)$ & $( \pm 0 \cdot 018)$ \\
\hline
\end{tabular}

TABLE 4

Outcrossing frequencies ( $t)$ of radiate $\left(\mathrm{T}_{\mathrm{T}} \mathrm{T}_{\mathrm{T}}\right)$ and non-radiate $\left(\mathrm{T}_{\mathrm{n}} \mathrm{T}_{\mathrm{n}}\right)$ plants in the Leeds, Cardiff and Rhosllanerchrugog populations together with heterogeneity $\chi^{2}$ comparisons. Standard errors are in parentheses

\begin{tabular}{cccc}
\hline Population & $\begin{array}{c}\text { Leeds } \\
\text { June 1979 }\end{array}$ & $\begin{array}{c}\text { Cardiff } \\
\text { June 1979 }\end{array}$ & $\begin{array}{c}\text { Rhosllanerchrugog } \\
\text { July 1979 }\end{array}$ \\
\hline $\mathrm{t}\left(\mathrm{T}_{\mathrm{r}} \mathrm{T}_{\mathrm{r}}\right)$ & $0 \cdot 060$ & $0 \cdot 137$ & $0 \cdot 351$ \\
& $( \pm 0 \cdot 008)$ & $( \pm 0 \cdot 008)$ & $( \pm 0 \cdot 032)$ \\
$\mathrm{t}\left(\mathrm{T}_{\mathrm{n}} \mathrm{T}_{\mathrm{n}}\right)$ & $0 \cdot 031$ & $0 \cdot 007$ & $0 \cdot 153$ \\
$\chi_{(1)}^{2}$ & $( \pm 0 \cdot 022)$ & $( \pm 0 \cdot 001)$ & $( \pm 0 \cdot 020)$ \\
& $1 \cdot 54$ N.S. & $230 \cdot 6^{* * *}$ & $26 \cdot 8^{* * *}$ \\
\hline
\end{tabular}

In all three populations radiate plants outcrossed at higher levels than non-radiate plants (table 4), though the difference in the Leeds population was not significant. The results from the Rhos population were of particular interest because of the relative high outcrossing rate of non-radiate plants, $15 \cdot 3$ per cent. This finding suggests that either as a consequence of genetic background or appropriate environmental conditions, the non-radiate variant can on occasion outcross in the wild, at frequencies similar to those that have been recorded previously for the variant under experimental conditions (Campbell and Abbott, 1976). 


\section{Discussion}

The results of the present investigations confirm that the greater outcrossing of the radiate morph relative to the non-radiate morph is a general feature of the ray floret polymorphism in $S$. vulgaris. The size of this difference, however, may vary greatly between years and locations. In the Newhaven Road population the outcrossing rate of the radiate variant exceeded that of the non-radiate variant by 35 per cent in June 1979; but in the following year, 1980, which was characterised by a spring drought and a dull wet summer in Edinburgh, the difference was of a much smaller magnitude, possibly as a result of reduced pollinator activity on the site.

Only in two instances was the difference between morphs not significant; at Edinburgh, in August 1980, and in the Leeds population sampled in 1979. At Leeds, radiate plants were observed to be non-randomly distributed in the population. Instead a pattern was present, with small numbers of radiate plants clustered together in groups amidst the large population of non-radiate plants. The occurrence of this pattern is likely to have caused the gene frequencies estimated for the adult flowering population on the site to be unrepresentative, indeed to be overestimates, of the frequencies of the non-radiate allele in the pollen pool available to radiate plants, and the radiate allele in the pollen pool available to non-radiate plants. As a consequence the outcrossing rate of each morph in the population may have been underestimated by the procedures employed (see Marshall and Abbott, 1982). Given the significantly greater outcrossing rate that is usual for the radiate variant, it is possible that the inaccuracies of the estimation procedure that accrue from a non-random distribution of morphs are more likely to affect the estimated outcrossing rate of the radiate morph than the non-radiate morph. This factor might thus account for the lack of a significant difference at Leeds.

That radiate plants outcrossed at rates greater than those exhibited by non-radiate plants in all populations surveyed, is strong evidence against the hypothesis that differences between morphs in outcrossing rate result from random linkage disequilibrium between alleles at the ray floret locus and alleles at other loci affecting outcrossing. It remains possible, however, that a disequilibrium may be maintained by selection in each population studied. To substantiate the alternative hypothesis, that the greater outcrossing of radiate plants is due to the higher outcrossing of ray florets relative to disc florets, will require a comparison of outcrossing rates in each of the two floret fractions.

In many studies, an estimation of the observed outcrossing rate and genotype frequencies in one generation of a natural population, is considered sufficient for the calculation of the expected genotype frequencies at a given locus (e.g., Harding and Barnes, 1977). The expected values obtained are useful in that they may be compared with the observed genotype frequencies and if a discrepancy occurs, an attempt can be made to determine which factors, other than mating system, are important in moulding the genotypic composition of the population (Brown, 1979). However, accurate estimation of expected genotype frequencies, based on data made available from a single generation, relies on the assumption that the population is at inbreeding equilibrium and, therefore, outcrossing rate is constant over generations; moreover, in most studies, it is assumed that all genotypes at the locus 
under investigation exhibit the same rate of outcrossing. In the present study, the radical changes in outcrossing rate that have been observed between years in the Newhaven Road population suggest that inbreeding equilibrium at the ray floret locus, is seldom achieved in polymorphic groundsel populations. In addition, it is clear that genotypic differences in outcrossing rates may always occur. Under these circumstances it would be incorrect to compare observed with expected genotype frequencies unless the expected frequencies were based on accurate estimates of outcrossing rates made for each genotype (including the heterozygote) in the parental generation of the population under study.

Though accurate estimation of expected genotype frequencies at the ray floret locus is not possible from the available data, nevertheless the greater selfing rate always shown by the non-radiate morph, leads to the expectation that in large populations the non-radiate morph should increase in frequency in subsequent generations, given that opposing factors, such as inbreeding depression (see Marshall and Abbott, 1982), are of an insufficient magnitude to counter the process. A detailed examination of the expected increase in frequency of the non-radiate morph together with the factors which might oppose it will be the subject of a future paper in this series (Marshall and Abbott, in prep.).

Acknowledgments D.F.M. is grateful for the support of a Carnegie Trust Scholarship throughout the period of study. We wish to thank Dr Stuart Davies and Miss Deborah Judd (U.C.W., Cardiff) for their advice and hospitality during our visit to Cardiff.

\section{REFERENCES}

BREESE. E. L. 1959. Selection for differing degrees of outbreeding in Nicotiana rustica. An. Bot., 23, 331-344.

BROWN. A. H. D. 1979. Enzyme polymorphism in plant populations. Theor. Pop. Biol., 15, 1-42. CAMPBELL. J. M. AND ABBOTT. R. J. 1976. Variability of outcrossing frequency in Senecio vulgaris L. Heredity, 36, 267-274.

CLAY, K. 1982. Environmental and genetic determinants of cleistogamy in a natural population of the grass Danthonia spicata. Evolution, 36, 734-741.

ENNOS, R. 1981. Quantitative studies of the mating system in two sympatric species of Ipomoea (Convolvulaceae). Genetica, 57, 93-97.

HAMRICK, J. L. 1982. Plant population genetics and evolution. Amer. J. Bot., 69, 1685-1693.

HARDING, J. AND BARNES, K. 1977. Genetics of Lupinus X. Genetic variability, heterozygosity and outcrossing in colonial populations of Lupinus succulentus. Evolution, 31, 247-255.

MARSHALL, D. F. AND ABBOTT. R. J. 1982. Polymorphism for outcrossing frequency at the ray floret locus in Senecio vulgaris L. I. Evidence. Heredity, 48, 227-235.

MARSHALL, D. F. AND ABBOTT, R. J. MS. Polymorphism for outcrossing frequency at the ray floret locus in Senecio vulgaris L. IV. Consequence. In preparation.

SCHOEN. D. J. 1982. The breeding system of Gilia achilleifolia: Variation in floral characteristics and outcrossing rates. Evolution, 36, 352-360.

TROW, A. H. 1912. On the inheritance of certain characters in the common groundsel, Senecio vulgaris L., and its segregates. J. Genet., 2, 239-276. 